\title{
Contexto, Experiência e Design
}

\author{
Marília Costa ${ }^{1}$; Renato Bedore ${ }^{2}$
}

\section{Resumo}

Este artigo traz como problemática as críticas recorrentes feitas ao ensino do Design no Brasil, apresentadas através de dois projetos realizados por estudantes de Design. A partir de um panorama sobre a docência no Ensino Superior brasileiro, foram definidos quatro principais pontos de insatisfação por parte dos estudantes: a relação com a autoridade, a flexibilidade da instituição, os métodos de avaliação e a experiência universitária. Esses pontos foram transformados em parâmetros para analisar três escolas europeias com métodos alternativos de ensino. Os resultados da análise mostram uma diferença contrastante em relação aos métodos de ensino em Design no Brasil, e levantam a discussão sobre a viabilidade da importação desses métodos e da mudança do sistema educacional vigente.

Palavras Chave: Ensino Superior; Ensino do Design no Brasil; Expedição Liberdade.

\section{Introdução}

O presente artigo foi produzido a partir do conteúdo apresentado para a primeira edição do evento de extensão SED - Seminários sobre Ensino em Design - como conclusão da disciplina de Metodologia no Ensino Superior, ministrada pelo professor Dr. Marcos Beccari no PPGDesign da UFPR. O problema tratado no seminário foram as principais críticas feitas ao ensino do Design no Brasil. O contexto para a apresentação partiu de três principais fontes.

A primeira fonte é o mini documentário "A Folha que Sobrou do Caderno", uma produção independente e sem fins lucrativos realizada pelos estudantes de Design Mauro Alex, Alexandre Czajkowski e Gabriel Costa. O curta foi apresentado no Ndesign Manaus em 2008 com a intenção de estimular o debate sobre o ensino do Design no Brasil. Entrevistando estudantes e professores de diversas instituições de ensino superior no país, o documentário mostra inúmeras críticas sobre o modelo de ensino atual, um modelo ulmiano, e apresenta

\footnotetext{
${ }^{1}$ Universidade Federal do Paraná, formada em Design Gráfico pela UFPR em 2015 e mestrado regular em Sistemas da Informação no PPGDesign da UFPR, com início em março de 2016. E-mail: marilia.amfc@gmail.com.

${ }^{2}$ Universidade Federal do Paraná, formado em Desenho Industrial com ênfase em Programação Visual pela UNESP em 2010 e mestrado regular em Sistemas da Informação no PPGDesign da UFPR, com início em março de 2016. E-mail: renatobedore080@gmail.com.
} 
como uma possível solução os movimentos estudantis, que confrontam o ensino formal das universidades.

Outro projeto que aborda a mesma temática é o trabalho de conclusão de curso apresentado na UFPR por Eric Schneider e Adhara Garcia em 2015, intitulado "Percepções sobre o Ensino de Design no Brasil: Por um aprendizado mais crítico e autônomo". Também através de entrevistas e depoimentos, os autores coletam uma série de opiniões de estudantes, professores e profissionais do design sobre o sistema de ensino nas universidades, separando em categorias, e comparam as informações coletadas com suas experiências de intercâmbio em universidades estrangeiras.

Os exemplos sugerem que há uma insatisfação geral com o atual modelo de ensino nos cursos de Design, e é dessa insatisfação que surgiu o projeto Expedição Liberdade, realizado em 2013 pelos ex-estudantes de design Daniel Larusso, Eduardo Cuducos e Mabel Lazzarim. O objetivo do projeto foi "conhecer e compartilhar experiências sobre espaços de aprendizado que buscam alternativas ao ensino tradicional" (LARUSSO et al., 2013, s.p.). A partir de um crowdfunding, eles conseguiram recursos para visitar 10 escolas -8 na Inglaterra, uma na Finlândia e outra na Dinamarca - e registrar o que viram.

O objetivo do presente artigo é analisar algumas dessas escolas através do viés da experiência e relacionar os resultados dessa análise às principais críticas ao atual sistema de ensino nos cursos de Design no Brasil, observando quais são as soluções dessas escolas para as principais críticas ao modelo de ensino vigente.

$\mathrm{Na}$ estrutura do artigo, em um primeiro momento é apresentado um breve panorama sobre a docência no ensino superior brasileiro, mais especificamente dentro do Design. A partir disso, são listados os principais pontos de insatisfação entre os estudantes, professores e profissionais da área, com base nos projetos apresentados anteriormente e nas aulas cursadas na disciplina de Metodologia no Ensino Superior, ministrada pelo professor Marcos Beccari. Esses pontos de insatisfação são então utilizados como parâmetros para analisar três escolas europeias visitadas pelo projeto Expedição Liberdade, seguindo sempre o "filtro central" da experiência significativa. Finalmente, os resultados da análise são discutidos e relacionados às principais críticas ao modelo de ensino vigente nos cursos de Design no Brasil. 


\section{O ensino superior brasileiro e a docência no Design}

Ferreira (apud SCHNEIDER e GARCIA, 2015, p. 52) descreve a chegada do ensino superior no Brasil como "mais um modelo importado tardiamente e de maneira distorcida, trazido sobretudo por motivos políticos”. Legado da Revolução Industrial, pouca coisa mudou nesse modelo desde então, que incentiva a produtividade extrema e tem como principal preocupação a inserção do aluno no mercado de trabalho. De acordo com Cavalcanti e Gayo (2004), os estudantes entram na universidade em busca de suas identidades e realização de suas potencialidades. O que encontram, porém, é a mera continuação do ensino fundamental e médio, com "programas pré-organizados em períodos e disciplinas, conteúdos selecionados e estabelecidos unilateralmente pelos professores ou pela instituição" (CAVALCANTI e GAYO, 2004, p. 48).

No Design não é diferente. O ensino do Design no Brasil sofreu influência direta da escola de Ulm e indireta da Bauhaus (BASSO e STAUDT, 2010). A ESDI - Escola Superior de Desenho Industrial - tinha como metas a abertura para a tecnologia e a aproximação da escola com a indústria, resquícios do modelo ulmiano reforçados por professores formados no exterior. As tentativas de copiar os modelos de ensino estrangeiros não só se mostraram precárias, como também atrapalharam o que poderia ter sido uma ótima oportunidade para criar uma proposta nacional (BASSO e STAUDT, 2010).

No documentário "A Folha que Sobrou do Caderno" e no TCC "Percepções sobre o Ensino de Design no Brasil", inúmeros estudantes, professores e profissionais do Design fazem críticas tanto ao ensino do Design no Brasil quanto ao Ensino Superior no geral. Essas críticas podem se enquadrar em quatro principais "categorias", que se relacionam e se complementam.

\section{Relação com a autoridade}

Na pesquisa realizada por Schneider e Garcia (2015), 56\% dos entrevistados associam suas principais experiências negativas de ensino à postura autoritária do professor. Rico Lins, designer formado na ESDI e ex-professor da NY School of Visual Arts, afirma que "o ambiente escolar, da maneira que é, pressupõe uma hierarquia da pessoa que sabe e das outras que não sabem (e logo, devem aprender)" (apud SCHNEIDER e GARCIA, 2015, p. 51). Herança do ensino tradicional, o que acontece é que o professor acaba por assumir esse papel 
de figura superior, que é a postura que esperam que ele assuma, enquanto os alunos cedem a essa autoridade, acomodando-se com esse sistema vertical de ensino.

\section{Flexibilidade da instituição}

Outra crítica diz respeito à estrutura das instituições de ensino, muitas vezes mais preocupadas com formalidades como grade horária, ensalamento e notas do que com o processo educacional em si. Os alunos são então forçados a se ajustarem a essa estrutura rígida (CAVALCANTI e GAYO, 2004). "A falta de espaço para que o estudante tome escolhas quanto à sua formação resulta em um sistema onde o aluno naturalmente assume uma posição passiva para cumprir regras e metas de uma formação institucionalizada" (SCHNEIDER e GARCIA, 2015, p. 56).

\section{Métodos de avaliação}

Os valores da instituição são refletidos nos métodos de avaliação da mesma. Aquino (2009) ressalta que, atualmente, o único objetivo das instituições de ensino parece ser atingir bons indicadores.

\footnotetext{
A atividade escolar consiste em "aulas", que os alunos "ouvem", e algumas vezes tomando notas, e em exames em que se verificam o que sabem, por meio de provas escritas e orais. Marcam-se alguns "trabalhos" para casa e, em casa, se supõe que o aluno "estuda" o que corresponde fixar de memória o quanto lhe tem sido, oralmente, ensinado nas aulas. Esta pedagogia podia funcionar perfeitamente numa escola da Idade Média. (TEIXEIRA apud CAVALCANTI e GAYO, 2004, p.48)
}

Essa avaliação parece desconsiderar a experiência e o processo de aprendizado do aluno. $\mathrm{O}$ estudante é avaliado pelo seu rendimento, o conhecimento é mensurado de maneira objetiva.

\section{Experiência universitária}

Todos os pontos levantados anteriormente resultam em uma experiência universitária insatisfatória. $\mathrm{O}$ aluno torna-se apático e descrente no sistema educacional, podendo assumir muitas vezes uma posição antagônica em relação à instituição. Cavalcanti e Gayo (2004) mostram três possíveis perfis para esses alunos: um passivo que aceita a realidade em que está 
inserido, que geralmente tem um bom aproveitamento acadêmico, porém se encontra despreparado ao ingressar no mercado de trabalho; outro rebelde, rotulado como indisciplinado, que buscará soluções em atividades extracurriculares como movimentos estudantis; e por fim um terceiro tipo de aluno que sucumbe ao ambiente inóspito, que se sente incapaz de seguir ou de mudar o sistema, o que pode levar ao abandono do curso, quadros de depressão e até, em casos graves, o suicídio.

A educação cartesiana (...) não consegue escutar o estudante, não consegue oferecer a ele um espaço para reflexões sobre quem ele é, sobre quais rumos quer seguir, e sobre como ele quer se relacionar com o mundo. Aliás, ao contrário, essas reflexões são evitadas na medida em que as respostas já estão dadas no modelo. Esse processo não dá espaço para a humanidade de quem aprende, para a luz que existe no estudante, para o desejo verdadeiro das trocas significativas que podem acontecer no processo de aprendizagem (LARUSSO et al., 2013).

No entanto, apesar das críticas, há uma vontade de modificar esse modelo industrial de educação, e existem várias escolas com métodos de ensino alternativos. Algumas dessas escolas foram investigadas pelo projeto Expedição Liberdade, e três delas foram analisadas no presente artigo.

\section{Experiência significativa}

Almeida (2015) descreve a experiência significativa como sendo algo que não acontece ao tempo todo, fora do banal do cotidiano, regulada pela intensidade estética em que ela acontece. Aqui se entende a estética pelo o viés das sensações e dos afetos que acontecem entre as relações.

(...) a experiência é o que nos passa, é o que nos afeta, é o que nos marca e depende sempre do encontro entre uma pessoa e uma ocasião, entre uma pessoa e um objeto, entre uma pessoa e outra pessoa. A experiência não é suscetível, portanto, ao controle. Pode-se buscar a ocasião, dedicar-se ao uso e à apreciação de um objeto, caçar paixões, entregar-se a pessoas, mas nenhuma dessas disposições é garantia de experiência. (ALMEIDA, 2015, p.141)

Larossa (2002) definiu que esse tipo de experiência deve partir de uma diferenciação social, o que pode ser entendido como uma predisposição a que algo nos aconteça ou ainda 
uma disponibilidade em experienciar algo marcante. Outro ponto importante delimitado pelo autor é o de que a experiência significava é individual e afeta (esteticamente) cada pessoa de forma particular e única.

\footnotetext{
"Experiência não é o caminho até um objetivo previsto, até uma meta que se conhece de antemão, mas é uma abertura para o desconhecido, para o que não se pode antecipar nem "pré-ver" nem "pré-dizer”" (LARROSA, 2002, p. 28).
}

É com base nessa perspectiva que iremos, neste artigo, analisar as descrições das amostras levantadas por Larusso et al no Projeto Expedição Liberdade.

\section{Método de análise}

Como método de análise, as críticas apontadas anteriormente foram transformadas em parâmetros para analisar três escolas visitadas pelo projeto Expedição. Cada parâmetro funciona como uma escala, com dois extremos, onde os métodos de ensino de cada escola podem encontrar-se em alguma extremidade ou em qualquer ponto entre elas. A divisão dos parâmetros ficou em:

- Relação com a autoridade: entre vertical hierárquico (uma relação mais vertical entre professor-aluno) e horizontal anárquico (uma relação mais igualitária entre professoraluno);

- Flexibilidade da instituição: entre uma instituição com foco em uma instrução predefinida, com pouca flexibilidade, e uma instituição com foco em uma autoformação livre, com muita flexibilidade;

- Métodos de avaliação: entre um modelo tradicional de avaliação, com base em comparação e mérito, e um modelo construtivista de avaliação, onde o processo de aprendizado conta mais que o resultado final;

- Experiência universitária: entre uma experiência rotineira, onde o aluno faz parte de uma massa e é tratado como todos os outros, e uma experiência estética, onde o aluno é visto como um indivíduo único e tem espaço para refletir e opinar. 


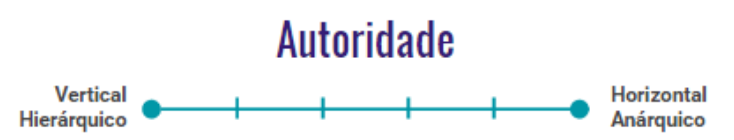

Instituição

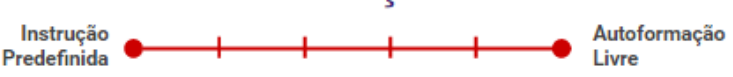

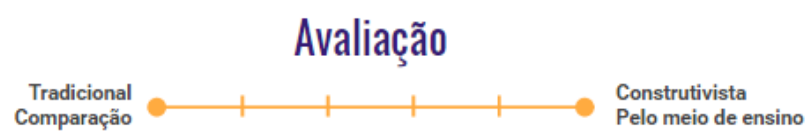

Experiência

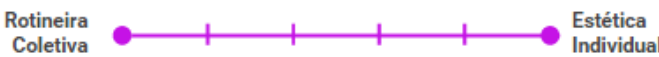

Figura 1: Parâmetros de análise (Os autores)

\section{Amostras}

Diante das nove escolas abordadas pelo Projeto Expedição, selecionamos três que apresentam métodos e dinâmicas mais contrastantes, para que a análise posterior fosse heterogênea.
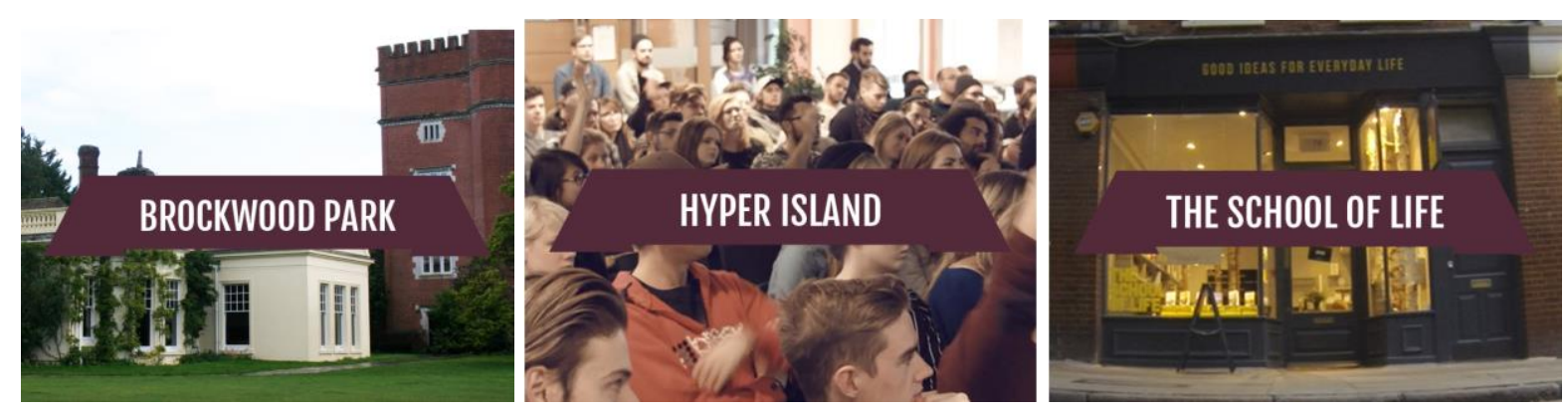

Figuras 2, 3 e 4: Escolas selecionadas (www.expedicaoliberdade.com.br)

\section{Brockwood Park}

Escola localizada em uma região rural em Hempshire na Inglaterra, entre as cidades de Petersfield e Winchester. É voltada para o ensino de conhecimentos gerais para adolescentes. Seu método de ensino é baseados nos conceitos criados por seu fundador o filósofo indiano Krishnamurti e pode ser resumido em três palavras-chaves: igualdade, autonomia e livre interação.

- Todos os membros têm rotinas conjuntas (diretor e alunos limpam a escola juntos);

- O aluno escolhe o que quer estudar;

- Se algo está ruim, os discentes e os docentes conversam a respeito e mudam;

- O aluno deve passar por uma semana de experiência prévia antes de ingressar no programa; 
- O que interessa não é saber se a resposta está correta, mas entender como cada um chegou até ela.

\section{Hyper Island}

Escola localizada na cidade de Manchester, na Inglaterra. É voltada para o ensino de conceitos, teorias e técnicas para empreendedores. Seu método de ensino é baseado na prática mercadológica e na gestão de projetos e pode ser resumido em três palavras-chaves: criatividade, tecnologia e negócios.

- Espaço de formação que transita por várias áreas do conhecimento;

- Programa estrutura-se de acordo com as necessidades externas providas pelo mercado;

- A escola abriga experts do mercado, que são referência em suas respectivas áreas;

- Ciclo focado no experimentar e refletir;

- Acertar ou errar não é importante.

\section{The School of Life}

Escola localizada em Londres e com subsedes em outras partes do mundo. É voltada para o estudo de questões fundamentais da vida humana. Seu método de ensino é variado e ocorre com diferentes tipos de dinâmicas, pode ser resumido em três palavras-chaves: cotidiano, emoções e relacionamento.

- Foco em questões fundamentais da vida humana;

- Desenvolver inteligência emocional através de novas experiências;

- Diferentes formatos de abordagem (sermões, tours, aulas, workshops, terapia etc);

- Professores de diferentes áreas do conhecimento (filósofos, artistas, executivos, etc), referências sociais.

\section{Resultados}

Como síntese dos resultados analisados é possível afirmar que todas as escolas funcionam com o ensino por meio da experiência, o que acaba por colocar o aluno como autor 
participativo do processo de aprendizagem por meio da autoformação estética individual de cada um, buscando provocar assim que ocorra a experiência significativa.

Com relação ao tema da autoridade, todas as escolas tratam este assunto de maneira horizontal e dividida igualitariamente entre todos as partes ativas no processo de aprendizagem (docentes e discentes), conferindo aos alunos responsabilidades e funções no processo de estruturação das emendas e dinâmicas estruturais da escola. Outro ponto em comum nas amostras é que todas tem o conceito de "projeto coletivo" como centralizador e catalisador multidisciplinar de todos os temas abordados dentre das instituições.

Por fim, todas as instituições levantadas neste artigo funcionam com o conceito de avaliação livre, muitas vezes promovidas pelos próprios alunos ou apenas pelo resultado da aceitação ou não do projeto coletivo pelo mercado.

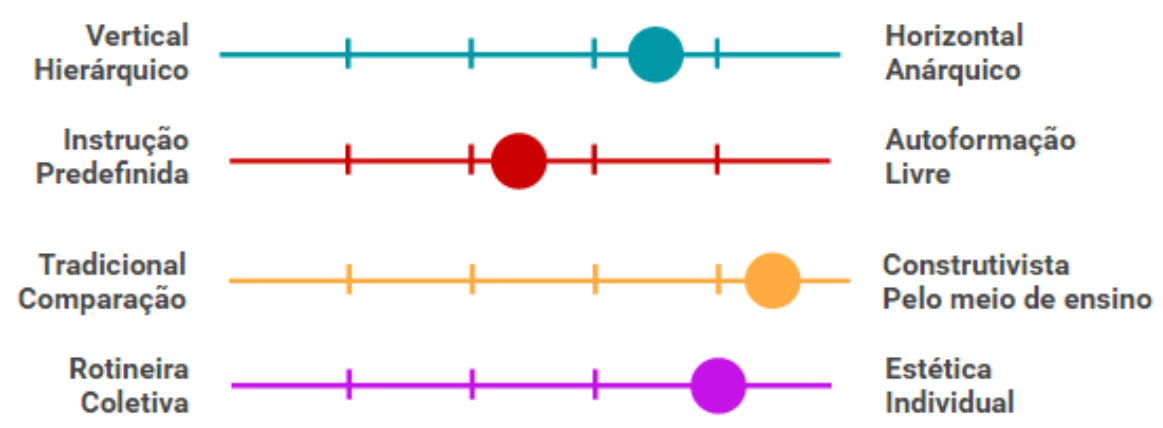

Figura 5: Média geral dos posicionamentos de cada escola (Os autores)

\section{Desdobramentos}

Com base nos assuntos tratados neste artigo e após a síntese dos resultados encontrados, ressalta-se que esse tema ainda tem muito a ser explorado em pesquisas futuras, por ser um tema complexo e longe de ter seu entendimento pleno pelas bases teóricas aqui levantadas. Sendo assim, foi possível destacar alguns questionamentos e desdobramentos deste campo de estudo prévio, com o objetivo de indicar caminhos possíveis de serem desenvolvidos em estudos futuros.

Um desses desdobramentos seria analisar a possibilidade de aplicação dessas estratégias das escolas inovadoras dentro de instituições de ensino de Design no Brasil. E, se isso fosse possível, quais adequações deveriam ser feitas nos dois modelos de ensino levando em consideração o choque cultural entre os países. 
Outro caminho a ser explorado seria o estudo da viabilidade de coexistência entre os modelos tratados nas escolas inovadoras aqui apontadas e as instituições de Ensino de Design no Brasil tradicionais já estabelecidas.

\section{English Title: Context, Experience and Design.}

\section{Abstract}

This article brings into discussion the frequent criticism to the way Design is taught in Brazil, presented through two different Design student's projects. From an overview about the Higher Education teaching in Brazil, four main student dissatisfaction points were defined: the relationship with authority, the institution's flexibility, the evaluating methods and the university experience. These points were turned into parameters to analyze three European schools with alternative teaching methods. The analysis results show a contrasting difference in relation to the Design teaching methods in Brazil, and raise the discussion about the viability of importing these methods and changing the current educational system.

Keywords: Higher Education; Design Teaching in Brazil; Expedição Liberdade.

\section{Referências}

ALMEIDA, R. de. O mundo, os homens e suas obras: filosofia trágica e pedagogia da escolha. Tese (Livre-docência em Filosofia da Educação) - Universidade de São Paulo, São Paulo, 2015.

AQUINO, J. Docência, Poder e Liberdade: Dos processos de governamentalização à potência de existir nas escolas. Tese de Doutorado. Departamento de Filosofia da Educação e Ciências da Educação. Universidade de São Paulo, 2009.

BASSO, C; STAUDT, D. A influência da escola de Ulm e Bauhaus na estrutura curricular das escolas. Revista Conhecimento Online, vol 2. 2010.

CAVALCANTI, R; GAYO, M. Andragogia na educação universitária. 2004.

Documentário. A Folha que sobrou no caderno. (2008) Mauro Alex, Alexandre Czajkowski e Gabriel Costa. Disponível em: 〈https://www.youtube.com/watch?v=aMXdyTEqrUw>. Acesso em: 09/2016. 
GARCIA, A; HAN, E. Percepções sobre o Ensino de Design no Brasil: Por um aprendizado mais crítico e autônomo. Trabalho de Conclusão de Curso. Setor de Artes, Comunicação e Design. Universidade Federal do Paraná, 2015.

LARROSA, J. Notas sobre a experiência e o saber da experiência. Revista Brasileira de Educação, n.19, 2002, p. 20-28.

LARUSSO, D. CUDUCOS, E. LAZZARIM, M. Expedição Liberdade. (2013) Disponível em: <http://expedicaoliberdade.com.br>. Acesso em: 09/2016 